\title{
Data heterogeneity and oldness, two difficulties to overcome for the world seabed sediment mapping
}

\author{
T. Garlan ${ }^{\mathrm{a}, *}$, I. Gabelotaud ${ }^{\mathrm{a}}$, E. Marchès ${ }^{\mathrm{a}}$, E. Le Borgne ${ }^{\mathrm{a}}, \mathrm{S}$. Lucas ${ }^{\text {a }}$ \\ aShom,thierry.garlan@shom.fr, isabelle.gabelotaud@shom.fr,elodie.marches@shom.fr,edith.le.borgne@shom.fr, \\ sylvain.lucas@shom.fr \\ * Corresponding author
}

\begin{abstract}
A global seabed sediment map has been developed since 1995 to provide a necessary tool for different needs. This project is not completely original since it had already been done in 1912 when the French hydrographic Office and the University of Nancy produced sedimentary maps of the European and North American coasts. Seabed sediments is one of the last geographical domains which can't benefit of satellite data. Without this contribution, sediment maps need to use very old data mixed with the new ones to be able to reach the goal of a global map. In general, sediment maps are made with the latest available techniques and are replaced after a few decades, thus generating new cartographic works as if all the previous efforts had become useless. Such approach underestimates the quality of past works and prevents to have maps covering large areas. The present work suggests to standardize all kind of sedimentary data from different periods and from very different acquisition systems and integrate them into a single product. This process has already been done for bathymetric data of marine charts, we discuss in this article of the application of this method at a global scale for sediment data.
\end{abstract}

Keywords: marine sedimentology, seabed sediment, map fusion, world ocean

\section{Introduction}

Currently, the mapping of marine sediments is based on the fusion of various acoustic data coupled with the results of analyses of sediments that have been taken from the sea bottom. But this was not always the case. The seabed maps were previously carried out from sediment samples taken with dredges or skips, and in even older times the cartography was carried out from the visual description of the sediments obtain with lead lines by hydrographers. The hollowed bottom of the lead line was used to insert a piece of tallow, the sediment stuck could be then described. The first series of descriptions of the bottom nature date back to the 1750s (Rawsthorne, 2020), then the first bottom seabed sediment map based on lead lines and on the first grab samples dates from 1897 (Garlan, 2012). Maps based on dredging, grab and core samplings then became widespread from the 1960s and are still published regularly in particular in Great Britain and Japan, but they have partly given way to maps based on reflectivity data. These one appeared at the end of the 1980s with the interpretation of side scan sonars (SSS) imagery mosaics then from those obtained using Multibeam Echo Sounders (MES). During these 270 years of the development of sedimentology and of the 120 years of sediment mapping, the evolution of techniques has been followed by an evolution of sediment mapping methods. This approach of taking only the recent data acquired with the latest acquisition method makes it possible to agree with the most modern techniques, but this approach has the disadvantage of always restarting from a zero state of knowledge.

If the same approach were applied in bathymetry, only a few percent of the charts concerning the continental shelves would have bathymetric information. For nautical charts, the oldest probes are gradually replaced but probes from surveys carried out with lead lines still remain on nautical charts. Likewise, to progress in the field of marine sediment mapping, it is essential to base the cartography approach with the use of old data and to gradually improve the map obtained as more recent data is added. Such an approach is particularly essential for the realization of a world map of marine sediments, but even for coastal maps at 1: 50,000 such an approach is necessary to be able to meet the needs of the protection of benthic habitats or to look at general impacts of pollution. Only accurate impact studies for the establishment of wind farms, for the opening and monitoring of aggregate exploitations or for the laying of submarine cables require high resolution maps. At these accurate resolution data must be acquired during a short period of time to not be perturbed by sediment dynamics. And even in these cases sediment mappings based on old data is necessary in order to assess the temporal variability of the seabed. Here again we find a symmetry with the bathymetrical data of the nautical charts. Indeed, at scales of $1 / 50,000$ the bathymetry can be estimated to be stable over a period of several decades. 
But at a scale of 1: 10,000 to 1: 25,000 DEMs present fine structures such as marine dunes which present displacements becoming visible in a few years scales. Thus, the cross-use of sediment data from different ages must be linked to the use of the map and scale of the documents.

The present works therefore concern seabed sediment maps from regional up to the global scale. The production of sedimentary maps by the Shom resulted in maps based on such an approach for the 1/ 50,000 coastal area French coast (Garlan, 1993) and for the seabed sediment world map (Garlan et al., 2018). Such an approach requires having a classification independent of the acquisition systems and having standardized data within a Database integrating point and area data. Thus, like other sciences, sedimentology is subject to a growth and diversification of the techniques employed, increased interaction with other sciences in particular biology and a fragmentation of information. In addition, it is subject to difficulties specific to earth sciences, such as uncertainties regarding the dating of events versus sediment dynamics, and normalization problems. The purpose of this work is to show that it is possible to improve knowledge by structuring sedimentary maps on data from the past and then enriching them with data from the most modern methods. The structuring of this data and its management allows a rich mapping of centuries of data acquired without having to wait for global coverage. The history of sedimentology shows that new techniques always appeared before a comprehensive coverage was achieved with an acquisition method. As a complete coverage by sedimentological data of the oceans would require more than a century of measurements with the current technologies and nautical means, it is applied a method of management of every past and present data. The objective is to have the best possible representation and to answer most of the needs for knowledge of the seabed, which have multiplied in recent years because of the growing needs for the development of MREs, for the extraction of sand and aggregates, but also and above all the growing need to protect marine habitats.

\section{A brief history of sediment mapping}

\subsection{Seabed sediment maps}

Unlike bathymetric maps (which always show depth data), sedimentological maps may include varied information, e.g. particle size, chemical components, physical processes, geomorphology, geology. Since the emergence of side-scan sonars in the 1980s, many published maps are based on reflectivity data calibrated by grain size analysis of samples, simultaneously maps based essentially on samples extend the techniques that appeared in the 19th century with lead lines used to acquire bathymetry and the nature of the seabed, then samples were taken with skips, dredges and corers. All coastlines of French metropolitan and overseas territories were hydrographically surveyed with tallowed lead lines between 1750 and 1940. These surveys were very closely gridded near the coasts, with sounding points spaced from 20 to $40 \mathrm{~m}$ along profiles spaced from 75 to 120 meters. With millions of seabed observations made, the period from 1750 and 1940 is very rich in marine sediment characterization and seabed maps can be directly made with them. The particle size data replaced the visual descriptions of sediment from the beginning of the twentieth century. These sampling data are mandatory to perform the calibration of the acoustic data, because whatever the improvements in the performance of side sonars, MES and seabed classification systems, these one do not allow to define the sediment nature in the absence of samples. The reflectivity of the bottoms obtained with such acoustic systems depends on the frequency, the surface investigated, the proximity of the bottom and several characteristics of the sediment.

\subsection{The stages of techniques diversification}

For a given frequency and angle of incidence, these systems provide information combining the granularity, the roughness of the surface (with a strong impact of wrinkles, algae and the heterogeneity of the particles), and the nature of the interstitial fluids. The frequent presence of gas in clays gives for example a strong reflectivity comparable to that provided by certain rocks. It follows that the sedimentary limits varied from one system to another or depending on the environment conditions. More discriminating, seabed classification systems, such as Roxann (Pace, 1990) or QTC (Prager et al., 1995), used at frequencies sufficiently low to penetrate the sediments $(<100 \mathrm{kHz})$ but high enough not to cross several layers of sediment (> $30 \mathrm{kHz}$ ), provide a solution for coupling the punctual view of the sample to the area distribution. These data are also affected by the roughness of the bottom and by the nature of the pore fluids, and therefore also require sediment samples to allow mapping, but they have the advantage of better representing the variability of the bottoms by discriminating a wide range of sediments. Where MES and SSS are limited to the delineation of a few sediment facies, the Seabed Classification System (SCS) give the more discriminating data to represent the great variability of seabed sediment. An analysis of sediment samples by sieving for coarser sediment, and by laser granulometry and / or by camera particle size analyzer for the finest ones, makes it possible to provide from sediment samples a very accurate description of the size, shape, nature and heterogeneity of the sedimentary particles. Some countries such as Portugal (Instituto Hidrografico, 1985) or Japan (Katayama et al, 2000) have initiated since several decades very useful sediment sampling campaigns using a regular grid, even in these cases the grid remains 
quite wide. In the other regions of the world the distribution of such data is very inhomogeneous and always far below requirements. Such a sampling-based approach has the advantage of allowing mapping using non-linear geostatistical techniques (Rosa et al., 2013). But it always underestimates rock outcrops, furthermore the acquisition costs at sea and the time processing for each sample limit this approach to regions where highresolution studies are carried out on the geochemistry of sediments or on studies of the impact on pollutants. For these approaches the global knowledge is still poorer. From the first data acquired with lead line in 1750 until the 1980s, the data used for the mapping of the distribution of sediments was based on samples. To which some researchers enriched their expertise by taking into account the morphology of the seabed extracted from the bathymetry. The density of the lead lines data was able to reach at the end of the $\mathrm{XIX}^{\text {th }}$ century up to 177 points / $\mathrm{km}^{2}$, for example near certain sectors of the French coasts. It is for these areas possible to limit the importance of the interpretation when drawing the limits of extension of the different sedimentary facies.

The distance between samples was then spaced degrading the seabed maps quality and it was not until the arrival of acoustic systems at the end of the 1980s to find again a surface vision of the seabed. It permits to precisely characterize the extension of rock outcrops, and permits to reveal quantities of sedimentary structures such as dunes, sandy ribbons, pockmarks, mud volcanoes ... which had previously been described in sedimentary rocks but which have only been recognized on current seabed during last decades. The cartography then focused on these new data which revolutionized the knowledge of the seabed focusing the cartography on the sedimentary structures and not on the constituents of the bottom as it could be before. The mapping of sediments has thus evolved over the ages in line with technical progress. Maps based on high densities of visual descriptions of lead lines were followed by maps based on scattered samples taken with sediment samplers, then came the morpho-structural maps from Side-scan sonar imagery and then from reflectivity data of MES. In the 1940's with the advent of acoustic echosounders, a distortion had appeared between bathymetric acquired on profile and sedimentary data which implied stations and maneuvers.

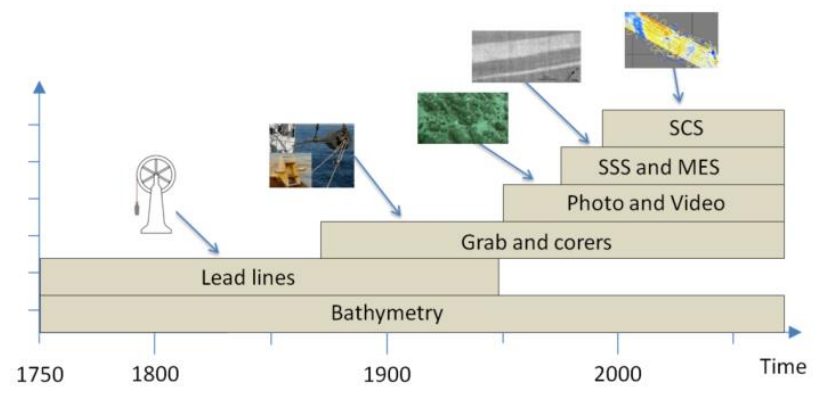

Figure 1. Evolution of systems used to define seabed sediment.

It was not until the advent of MES and supervised seafloor classification systems in the 1990's that the sedimentology could develop again. Thus, the sediment data acquisition systems have followed one another over time, making it possible to gradually increase the information on the sediments and permitting to discover the great variability of the seabed (Figure 1). But even at present sedimentologists do not have a system that alone can provide the name of the sediments covering the seabed.

\section{Synthetic mapping applied to marine sediments}

In France, as in United Kingdom or other countries with great marine areas, sedimentary surveys carried out each year by public offices, research laboratories and private societies cover less than $1 \%$ of their continental shelf. Navigation channels or areas including infrastructure such as Marine Renewable Energy (MRE) require recurring surveys, implying that in many sectors surveys are more than one hundred year spaced, sometimes more than 1.5 century. Thus, not being able to benefit from the contribution of satellite data, studies of marine sedimentology are based on costly nautical resources which imply long time. Thus, the possibility of achieving a mapping of the continental shelves with the quality permitted by current systems is not possible in this century. To add a level of complexity, it should be noted that: the different sampling systems (dredge versus grab versus corer), laboratory analysis methods (sieving versus laser grain size measurement), the acquired frequency and accuracy of acoustic systems as well as the temporal variability of seabed resulting from sediment dynamics and human activities, are all elements impacting the data used for sediment mapping. These differences arise for example from the objectives of the sedimentary surveys which will motivate different methodologies if the surveys are carried out for hydrography, for geochemical studies of pollutants or for research of the distribution of benthic habitats.

The seabed is subjected to the action of tidal currents and storms which generate sediment dynamics on all or part of 
the continental shelf. Further offshore, from the summit to the base of the continental slope, phenomena of up-welling currents, deep bottom currents, and underwater avalanches can also locally generate temporal variability of the sediments. In addition to these natural changes, there are anthropogenic activities such as the resuspension of sediments by trawling and the dredging of sand for beach nourishment, navigation or the supply of raw materials, which can sometimes durably modify the constituents of the seabed. wait for the next century, it is necessary to define specific mapping methods based on the fusion of all available knowledge.

In the 1960s many national mapping programs were developed over the world, but only some of them continue today, so the map of some regions is based exclusively on data from the last century.

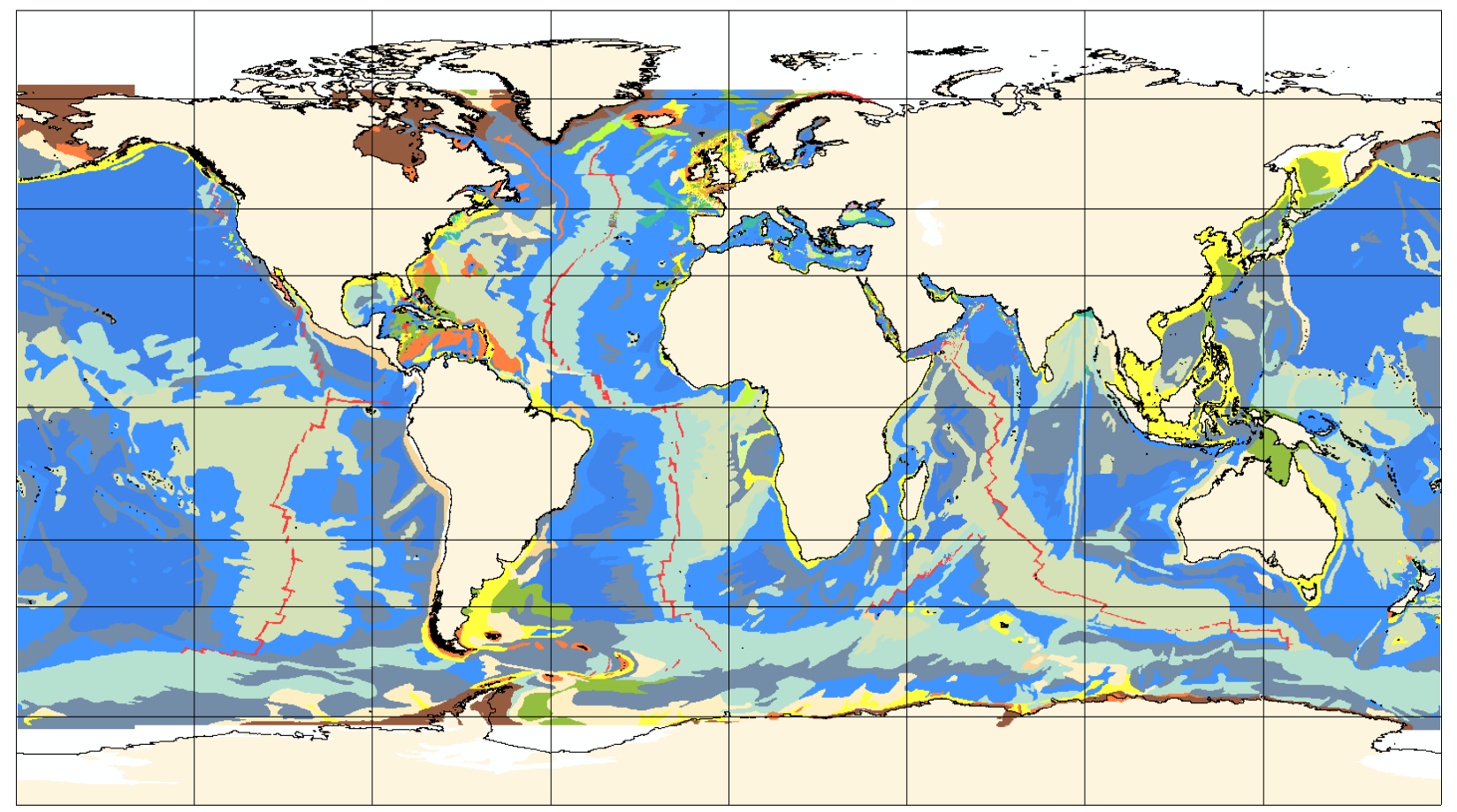

Figure 2 : The global seabed map with 27 sediment classes (Shom, 2020)

Through its impacts and relationships with coastal dynamics, with carbon sequestration, with protection of marine habitats, and with MRE development the needs for knowledge of the distribution of marine sediments are strongly increasing. When these needs are confined to a restricted area, for example for the installation of wind turbines or the protection of a Marine Protected Area, specific surveys are carried out and allow a cartography of the sediments at high resolution, that is to say at scales ranging from a few thousandths to $1: 20,000$.

At these scales the sediment dynamics can be visible over a short period of a few months to a few years. This high resolution is therefore associated with a date of obsolescence. The use of older data is in this case limited to the studies of the temporal evolution of the seabed. For other studies, for regional or global researches or to determine the distribution of marine species, or for studies of climate change and carbon sequestration, more general maps are needed. To meet these needs without having to
After the end of the French national program at the end of the 1970s, a new program was initiated in 1990 by the Shom in France. It is ranging from very high resolution maps to a series of 1: 50,000 and 1: 150,000 maps along the French coast. During these programs, a global seabed sediment map was initiated in 1996. For each range of scales, a methodology is applied

using different data sets according to the scales but all responding to a unique standardization regardless of oldness and of the type of data used. This standardization is done by means of a Database which contains all the data necessary for the realization of the maps, but it also permit to manage the different versions of the maps thus produced. This approach consists of taking the information of the best quality for each location. A primordial element is to have a sufficient expertise to integrate new components in the complex system constituting the seabed, with all its regional specificities. 


\section{The global seabed sediment map}

The coverage of the world map has not changed since the initial version. It covers all the seas of the world except the Arctic and the Antarctic, beyond latitude: $+72^{\circ}$ and $-72^{\circ}$ which represents $96.6 \%$ of the surfaces covered by seas and oceans. On diffusion.shom.fr the shape file of the 11th version of the digital world sediment map in the WGS84 datum is open source. The equivalent scale for paper documents of this product would be in the range of 1 : 500,000 . This seabed map is based initially on a map of the oceans entitled "Sedimentary Map of the World", realized by UNESCO, digitized by the Shom in 1995, the original classification has been modified according to the sediment classification used by the French hydrographic Office (Garlan, 2004) for its Sedimentary databases. The classification contains one class for rocks, 5 sediment classes for cobbles, gravel, sand, fine sand and mud. When the information allows it, mud is separated into silts and clays. To these homogeneous sediments are added 18 classes of binary mixtures of the preceding elements. The very imprecise initial map was intended to provide everywhere basic information on the nature of the seabed, but it in fact only concerned the deep sea and most of the coasts were assimilated to sand deposits. In a second step, the quality of this map has been enhanced by sectors, starting with the North Atlantic and the Mediterranean. This sediment map has been progressively improved by integrating more accurate maps, produced by Shom, or old digitized and then standardized sediment maps published mainly by French organizations. The first versions of the world sediment map were used exclusively for the needs of the Shom, since 2012 it is open source distributed. The eleventh version is the fusion of 283 seabed maps. These maps are selected when the area they cover is sufficiently large, and when their quality and the value of their content permit to enhance the global seabed map (Figure 2). The maps integrated in the global map range from 1921 to 2016. These new data come from maps at scale from $1 / 100$ 000 to $1 / 1000000$. They can come from old lead lines, it is for example the case of the map of the north Vietnam shelf which had been realized to make a synthesis of thousands of lead lines done by the French Hydrographic Office in Vietnam in the 1920s. The previous versions of the global seabed map showed sand on this zone. It has been necessary to make a correction of the surrounding sediments which was initially sand (Figure 3). In most cases new data is more in conformity with the original data. This representative example of the intertropical environment would indicate that the sand surfaces must be lower than what is currently shown on the map (figure 2).

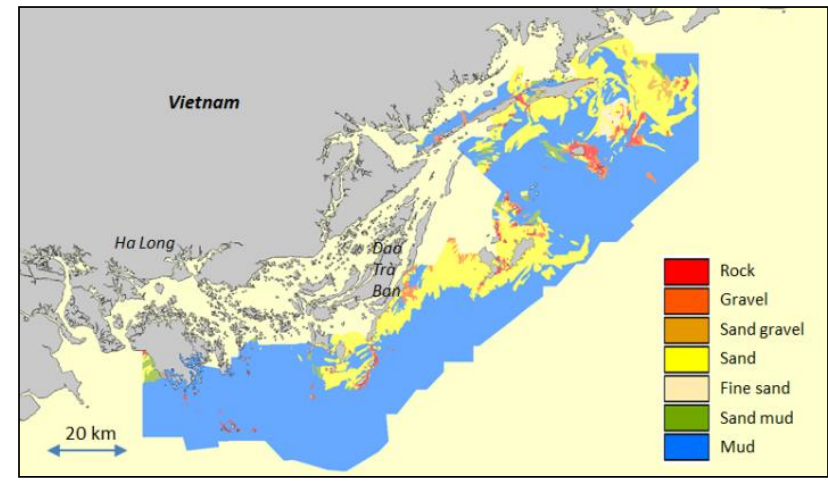

Figure 3: Seabed map of the Bay of Ha Long from 1920s lead lines (Shom, 1996) superimposed on the global seabed sediment map (Shom, 2020)

For the ten editions since 2000, the improvement focused on the littoral domain which presents a greater spatial variability of the sediments. The improvement between the versions results in a better representation of the limits between the sedimentary facies, but also on the increase in the number of polygons of sediment areas. Thus in 20 years, the number of polygons has increased from 2389 to 35655 (Figure 4).

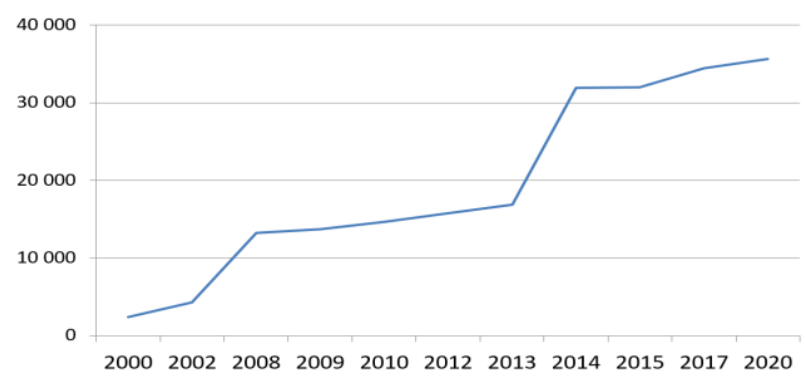

Figure 4: Number of polygons of successive global seabed sediment maps

The small amount of map added in the southern hemisphere implies that the total number of polygons of the southern hemisphere represents only $5 \%$ of the total number of polygons of the world map.

\begin{tabular}{|l|l|l|l|l|l|}
\hline & Rock & $\begin{array}{l}\text { Pebble \& Sand \& Mud } \\
\text { Gravel }\end{array}$ & $\begin{array}{l}\text { Fine sand \& Silt } \\
\text { Flay }\end{array}$ \\
\hline $\begin{array}{l}\% \text { of } \\
\text { polygons }\end{array}$ & 39 & 16 & 37 & 7 & 1 \\
\hline $\begin{array}{l}\% \text { of } \\
\text { Surface } \\
\text { covered }\end{array}$ & 0,9 & 2,3 & 9,8 & 50,6 & 36,4 \\
\hline
\end{tabular}

Table 1: Percentage of polygons and surface areas covered by the different types of seabed sediments of the world map

The global seabed sediment map allows us to approximate the surfaces covered by each type of sediment (Table 1). The high proportion of clays, silts and mud (87\%) is due to an over-representation of these sediments on the deep seabed. Deep-sea sediments in the 1960s were known only by sparse samplings so the extension of rocky areas and of 
muddy sand turbidite fans, are probably underrepresented. In the deep sea, several dozen of MBES surveys have been integrated, the improvement of quality obtained in these some cases is visible for example on the south-east Indian Ocean ridge (Figure 5), with a more accurate location and an organization always more intricate than old data. On continental shelf, the integrated maps have gradually made it possible to refine knowledge. The improvement by each map is very variable, it can be very important when a map replaces a homogeneous area with more than 500 polygons such as for example the map of Vietnam (figure 3) or the map of Long Island from NOS (1989).

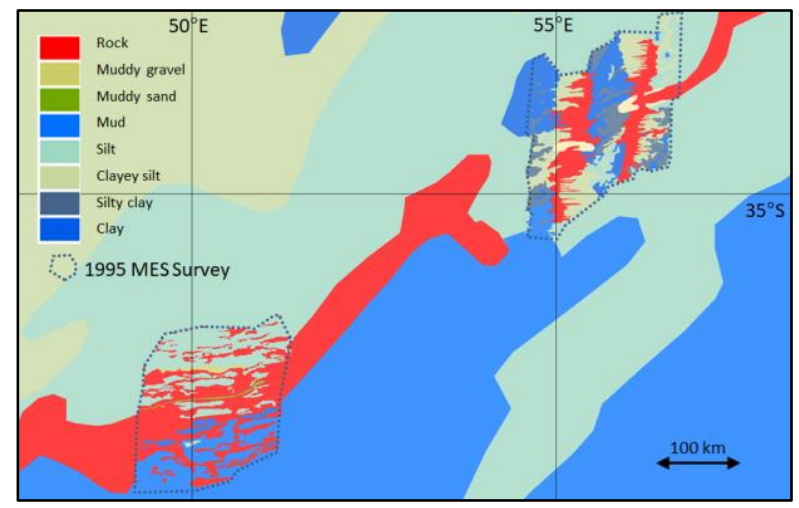

Figure 5 : Example of 2 maps from 1995 geophysical surveys of the Southern Indian Ocean (Sauter, 2009), analyzed, formatted and integrated into the sedimentary world map.

The comparison of the areas covered compared to the number of polygons for each type of sediment (figure 6) shows an over-representation of the rock represented by $39 \%$ of polygons when they represent only $0.9 \%$ of the world seabed surfaces. Such an analysis will be continued but it will require sectoring according to depths or by regions. It could also be used for the different editions of the map in order to characterize more precisely the progress associated with this approach.

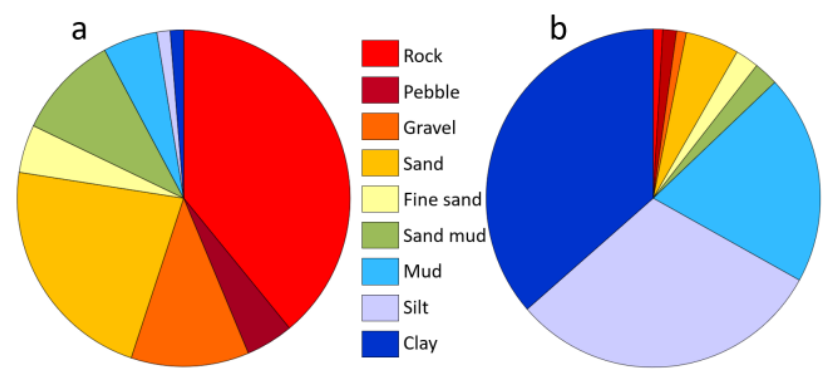

Figure 6: Percentage of polygons (a) and of areas covered (b) for the different seabed sediment types of the oceans

\section{Conclusion}

The approach presented here, makes the combination of data acquired with the most modern techniques with data extracted from old archives possible. This method benefits from the work carried out over more than a century. It allows to perform the mapping of vast areas for which no recent data, i.e. for the last 50 years, is available. It should be noted that this approach is in every way comparable to the one applied to bathymetric data for nautical charts. Some first analysis results show that this global seabed sediment vector map can be an interesting tool to look at the repartition of sediments. Many other applications can be done for example to make maps of the friction coefficient used to modelled currents or for acoustic propagation modeling. The distribution of this map on the web site diffusion.shom.fr allow everyone to use it as a support for these regional studies but can also serve as a basis for all applications requiring global knowledge. The quality of this world sedimentary map will have to be improved further for many years to bring it, in terms of percentage and areas covered, closer to the ground truth. In particular, efforts must be made in the southern hemisphere where little data has been incorporated into the old initial map.

\section{References}

Garlan, T. (1993). Innovations in Marine cartography at Shom. Int.Hydrographic Review, Monaco, LXX (1): 103-120.

Garlan, T. (2004). Apports de la modélisation dans l'étude de la sédimentation marine récente. Capacitation thesis to lead Research, University of Sciences et Technics of Lille: $155 \mathrm{p}$.

Garlan, T. (2012). Deux siècles de cartographie des sédiments marins. CFC - Cartes et Géomatique, 211: 115-139.

Garlan, T., Gabelotaud, I., Lucas, S., Marchès, E. (2018). A world map of seabed sediment based on 50 years knowledge. New York USA Jun 03-04, 2018, 20 (6) Part I : 139-149.

Instituto Hidrografico. (1985). Carta dos sedimentos superficiais de Cabo de S. Vicente ao Rio Guadiana. Instituto Hidrografico Ed., 1/150 000.

Katayama, H., Satoh, M., Ikehara, K. (2000). Sedimentological map of Gentatsu-Se. Geological survey of Japan, Marine Geology Map series, N`53, $1 / 200000$.

National Ocean Service. (1989). Bathymetric Fishing map: Long Island Sound-New Haven at 1/100 000. U.S. Dept of Commerce - National Oceanic and Atmospheric Administration/NOS.

Pace, N.G. (1990). Acoustic bacskcatter and sea bed characteristics. Proceedings of Institute of Acoustics, 12, 1: 21-31.

Prager, B.T., Caughey, D.A., Poeckert, R.H. (1995). Bottom classification: Operational results from QTC View. Oceans '95, San Diego, California: 8p. 
Rawsthorne, H. (2020). De la sonde à la carte - Une campagne hydrographique au XVIIIe siècle dans le golfe de Gascogne : analyse historique et traitement des données obtenues. Master 2 Épistémologie, histoire des sciences et des techniques, University of Brest : 295p.

Rosa, F., Rufino, M.M., Ferreira, O., Matias, A., Brito, A.C., Gaspar, M.B. (2013). The influence of coastal processes on inner shelf sediment distribution: The Eastern Algarve Shelf (Southern Portugal). Geologica Acta, 11, 1, 59-73

Sauter, D., Cannat, M., Meyzen, C., Bezos, A., Patriat, P., Humler, E., Debayle, E. (2009). Propagation of a melting anomaly along the ultraslow Southwest Indian Ridge between 46 degrees $\mathrm{E}$ and 52 degrees 20 'E: interaction with the Crozet hotspot ? Geophysical Journal International, 179(2), 687-699. 